\title{
Polymorphism in a T-cell receptor variable gene is associated with susceptibility to a juvenile rheumatoid arthritis subset
}

Walter P. Maksymowych ${ }^{1}$, Christos A. Gabriel ${ }^{1}$, Lorie Luyrink ${ }^{1}$, Hector Melin-Aldana ${ }^{1}$, Maruja Elma ${ }^{2}$, Edward H. Giannini, Daniel J. Lovell ${ }^{1}$, Catherine Van Kerckhove ${ }^{1}$, Jeffrey Leiden ${ }^{3}$, Edmund Choi ${ }^{2}$, and David N. Glass ${ }^{1}$

\footnotetext{
${ }^{1}$ Department of Pediatrics and ${ }^{2}$ Department of Molecular Genetics, Biochemistry and Microbiology, College of Medicine, University of Cincinnati, OH 45229, USA.

${ }^{3}$ Howard Hughes Medical Institute, University of Michigan Medical Center, Departments of Internal Medicine and Microbiology/Immunology, Ann Arbor, MI, USA
}

Received May 28, 1991; revised version received July 19, 1991

\begin{abstract}
This report demonstrates a T-cell receptor (Tcr) restriction fragment length polymorphism, defined by a $T c r b-V 6.1$ gene probe and $B g l$ II restriction enzyme, to be absolutely correlated with allelic variation in the coding sequence of a Tcrb-V6.1 gene. A pair of non-conservative amino acid substitutions distinguish the $T c r b$ V6.1 allelic variants. An association of this Tcrb-V6.1 gene allelic variant with one form of juvenile rheumatoid arthritis (JRA) was established in a cohort of 126 patients. The association was observed in patients possessing the $H L A-D Q A 1^{*} 0101$ gene. Among $H L A-D Q A^{*} 0101$ individuals, 19 of 26 patients $(73.1 \%$ ) carried one particular Tcrb-V6.1 gene allele as opposed to 11 of 33 controls (33\%; p <0.005). Haplotypes carrying this HLA gene have previously been shown to confer increased risk for progression of arthritis in JRA. This demonstration of a disease-associated $T c r b-V$ gene allelic variant has not, to our knowledge, been previously reported and supports the contribution of polymorphism in the Tcr variable region genomic repertoire to human autoimmune disease.
\end{abstract}

\section{Introduction}

Data on many of the HLA associations with autoimmune diseases have suggested the presence of other genetic factors, probably outside the major histocompatibility complex (MHC). The antigen-specific T-cell receptor (Tcr),

\footnotetext{
The nucleotide sequence data reported in this paper have been submitted to the GenBank nucleotide sequence database and have been assigned the accession numbers M67511 for V6.1A and M67512 for V6.1B. Address correspondence and offprint requests to: David N. Glass, Special Treatment Center for Juvenile Arthritis, Children's Hospital Medical Center, Elland and Bethesda Avenues, Pav 1-129, Cincinnati, OH 45229-2899, USA
}

which recognizes antigen only in the context of HLA molecules, seems a likely source of such effects. Interest has therefore focused on the Tcr $\alpha$ chain (Tcra) and $\beta$ chain $(T c r b)$ genes. The human $T c r b$ gene complex is located on chromosome 7. Transcription of the polypeptide follows rearrangement of discontinuous gene segments encoding variable $(V)$, diversity $(D)$, joining $(J)$, and constant $(C)$ regions in a manner analogous to the transcription of immunoglobulins. DNA sequence and Southern blot hybridization analyses have subdivided the $T c r b-V$ gene segments into 20 groups, or subfamilies, defined on the basis of nucleotide sequence homology (Barth et al. 1985). Each subfamily contains between one and ten members. Gene segments of different subfamilies are highly interspersed and may be spaced more than five kilobases (kb) apart (Lai et al. 1989). The $\alpha$ chain gene complex, located on chromosome 14, structurally resembles the $\beta$ chain complex (Davis and Bjorkman 1988).

Several studies have reported $T c r$ gene restriction fragment length polymorphisms (RFLPs) in a variety of autoimmune disorders, but were limited to description of $C$ region RFLPs which carried low relative risks (Millward et al. 1987; Demaine et al. 1989; Tebib et al. 1990). Recent family studies, demonstrating lack of linkage disequilibrium between $V$ and $C$ region genes of both Tcra and Tcrb gene complexes (Charmley et al. 1988; Charmley et al. 1990), indicate that further study should be directed primarily towards $V$ region genes, because they are the genes that most directly influence antigen-MHC recognition. Tcr- $V$ region genes may be studied indirectly by RFLP and directly by sequencedependent methods.

The present study has demonstrated the possible contribution of a $T c r b-V$ region RFLP to the inherited predisposition of a form of juvenile rheumatoid arthritis (JRA) for which HLA associations have been established. 
The absolute correlation of this RFLP with coding sequence variability in an adjacent $T c r b-V 6.1$ gene has been demonstrated. Finally, and most importantly, the association of a human autoimmune disease with allelic sequence variation in a variable region of the $\operatorname{Tcr} \beta$ chain is demonstrated.

\section{Materials and methods}

Patient population. One hundred and twenty-six unrelated Caucasian patients, well characterized with respect to HLA markers, were studied. All had early-onset pauciarticular juvenile theumatoid arthritis (EOPAJRA) as defined by the American College of Rheumatology criteria (Cassidy et al. 1986). Such patients are characterized by a pauciarticular onset (affecting four or fewer joints) in the first six months of disease, predominance of females $(88 \%)$, presence of antinuclear antibody (ANA), and the development of a chronic form of iridocyclitis. All patients had disease onset before the age of 8 years. The control group of 207 unrelated Caucasian individuals resembled the disease population with respect to geographic and ethnic (European) origin, both carrying a strong Northern European (German) ethnic component. This control series has been described previously (Maksymowych et al. 1991).

Tcr probes. The human Tcrb cDNA clone 4D1, a $1 \mathrm{~kb}$ cDNA isolated from the human T-cell tumor line HPB-MLT, contains the V6.1, D, $J$, and $C 2$ regions of the Tcrb chain (Jones et al. 1984; Leiden and Strominger 1986). This cDNA was subcloned in pUC19, and a specific $V$ region probe was derived by polymerase chain reaction (PCR) amplification of the $V$ region sequence using specific primers. The probe was labeled by random priming with $\left[\alpha-{ }^{32} \mathrm{P}\right]$-deoxynucleotide triphosphates (3000 Ci/mmol; New England Nuclear, Boston, MA) to specific activities ranging from $5 \times 10^{8}$ to $1 \times 10^{9} \mathrm{cpm} / \mu \mathrm{g}$ of DNA (Feinberg and Vogelstein 1983).

Tcrb-V6.1 associated RFLP. This polymorphism was detected as previously described (Maksymowych et al. 1991). The Tcrb-V6.1/Bgl II probe/enzyme combination defines a bi-allelic locus with polymorphic bands of 12.5 and $5.7 \mathrm{~kb}$.

DNA amplification and sequencing. Bg $l$ II restriction enzyme-digested genomic DNA, derived from five unrelated individuals homozygous for the $12.5 \mathrm{~kb}$ fragment and from five unrelated individuals homozygous for the $5.7 \mathrm{~kb}$ fragment, was run on agarose gels. Gel slices containing the polymorphic fragments were excised, isolated by phenol/chloroform extraction, and used as template for PCR amplification of the RFLPrelated $T c r b-V 6$ gene member. The sequences of oligonucleotides to be used as $\mathrm{Tcrb}_{\mathrm{B}} 6.1$ gene-specific primers were determined from the published sequence of the 4D1 cDNA that had served as the Tcrb-V6 gene probe. The primers were derived from the $5^{\prime}$ end and $3^{\prime}$ end of the 4D1 cDNA $V$ region sequence, (I. $5^{\prime}$ CCGAATTCGATGGGAGCTCAGGTGTGATC 3' sense; and II. 5' CCGAATTCACAGAGATACACGGCTGAGTCC $3^{\prime}$ antisense) so that the fragment amplified by these primers would include most of the exon encoding the Tcrb- $V$ gene segment [223 base pair (bp)]. Reaction mixtures ( 100 $\mu 1)$ containing template DNA, oligonucleotide primers $(1 \mu \mathrm{M})$, dNTPs $(200 \mu \mathrm{M})$ and 2.5 units of Taq I polymerase (Perkin-Elmer Cetus, Norwalk, CT) were subjected in a thermal cycler (Perkin-Elmer Cetus) to 30 cycles of denaturation $\left(95^{\circ} \mathrm{C}\right.$ for $\left.30 \mathrm{~s}\right)$, annealing $\left(55^{\circ} \mathrm{C}\right.$ for $\left.2 \mathrm{~min}\right)$, and extension $\left(72^{\circ} \mathrm{C}\right.$ for $\left.45 \mathrm{~s}\right)$. PCR-amplified Tcrb V6 gene products were checked by $1.5 \%$ agarose gel electrophoresis and ethidium bromide staining. Negative control samples were run with every PCR reaction. PCR reaction products were digested with Eco RI restriction enzyme (Pharmacia, Piscataway, NJ) in agarose (to cleave the $5^{\prime}$ ends of the primers) and extracted with phenol/chloroform. The digested DNA was ligated into an Eco RI-digested M13 mp19 vector, transformed into Escherichia coli JM109, and plated. Clones were screened by in situ plaque hybridization with the random-primer ${ }^{32} \mathrm{P}$-labeled $T c r b$-V6 cDNA probe. Purified DNA from positive clones was sequenced by the dideoxy chain termination method (Sequenase, US Biochemicals, Cleveland, $\mathrm{OH}$ ). All sequences were determined on both strands. At least three clones per DNA restriction fragment were sequenced in order to confirm sequence variation.

Dot-blot analysis. Members of the patient and control populations (patients $n=83$, controls $n=99$ ) were oligotyped for $T c r b-V 6.1$ gene allelic sequence variants. After PCR amplification of $1 \mu \mathrm{g}$ of genomic DNA using Tcrb-Y6 gene specific primers, $2 \mu \mathrm{l}$ of the amplified material was dot-blotted onto Nylon-66 membrane filters $(0.1 \mu \mathrm{m}$ pore size) (Schleicher and Schuell, Keene, NH). The following Tcrb-V6.1 gene allele-specific oligonucleotide (ASO) probes were synthesized (III. 5' CTGCCCAACGATCGGTT $3^{\prime}$ and IV. 5' CACAGAGCGGGGGGACT 3' designated $\mathrm{V} 6.1 \mathrm{~N}$ and $\mathrm{V} 6.1 \mathrm{R}$ respectively detecting sequence V6.1A. Two other probes (V.) 5' CTGCCCAAAGATCGGTT $3^{\prime}$ and VI. $5^{\prime}$ CACAGAGCAGGGGGACT $3^{\prime}$ were designated V6.1K and $\mathrm{V} 6.1 \mathrm{Q}$, respectively and detected sequence $V 6.1 B$. These probes were labeled with $\left[\alpha{ }^{32} \mathrm{P}\right]$-ATP and polynucleotide kinase and hybridized with the blots overnight at $37^{\circ} \mathrm{C}$ in $6 \times$ standard sodium citrate (SSC), $1 \times$ Denhardt's solution and $50 \mu \mathrm{g} / \mathrm{ml}$ low relative mass DNA. Blots were washed twice in $6 \times \mathrm{SSC}$ at room temperature, and $5 \mathrm{~min}$ at $57^{\circ} \mathrm{C}$ for probe III, at $53^{\circ} \mathrm{C}$ for probe IV, at $55^{\circ} \mathrm{C}$ for probe $\mathrm{V}$, and at $49^{\circ} \mathrm{C}$ for probe VI, followed by exposure to Kodak X-omat film for $2 \mathrm{~h}$. Positive and negative controls consisted of PCR-amplified genomic DNA from individuals homozygous for either the $5.7 \mathrm{~kb}$ or the 12.5 $\mathrm{kb} B g l$ II fragment, whose $T c r b$-V6. 1 gene alleles had been characterized previously by DNA sequencing and dot-blot analysis. Additional controls included phage supernatants, each sample containing a different Tcrb-V6.1 gene allele.

HLA typing. HLA-DR antigens in our entire study population were typed serologically according to standard techniques using antisera that included those tested by the eighth, ninth, and tenth Histocompatibility Workshops (Mittal et al. 1968). In addition, a previous study which included some subjects evaluated in the present study, had identified HLADQA $1 * 0101$ individuals as a distinct cohort of patients at increased risk for progression of polyarticular joint disease and a lower risk for the iridocyclitis of JRA (Van Kerckhove et al. 1991). $H L A-D Q w 1 \alpha$-chain alleles were therefore typed using allele-specific oligonucleotide probes following PCR amplification of the second exon of the DQ $\alpha$-chain using specific primers (Van Kerckhove et al. 1991). Typing results were available for 121 patients with EOPA-JRA and 202 controls.

Statistics. Statistical analysis was carried out using the chi-square test with one degree of freedom unless otherwise specified with adjustments for the number of comparisons made. P values were adjusted for multiple comparison using the Bonferroni correction.

\section{Results}

$T c r b-V b$ gene RFLP, HLA and disease. The distribution of $T c r b-V 6.1 / B g l$ II RFLP genotypes and allelic frequencies did not differ significantly between the total patient and control populations $\left(\mathrm{X}_{2}=1.24 ; \mathrm{p}>0.1,2\right.$ degrees of freedom; Table 1). However, comparisons made in the context of HLA type revealed that $H L A-D Q A l^{*} 0101$ patients differed significantly in their genotype distribution from $H L A-D Q A 1 * 0101$ controls, even after adjustment 
Table 1. Tcrb-V6.1/Bgl II RFLP genotypes in patients with EOPA-JRA and controls

\begin{tabular}{llll}
\hline \multicolumn{4}{c}{ RFLP genotype frequencies (n) } \\
\hline $\begin{array}{l}\text { Subjects } \\
\begin{array}{l}\text { Total patients } \\
(\mathrm{n}=126)\end{array}\end{array}$ & $5.7 / 5.7$ & $5.7 / 12.5$ & $12.5 / 12.5$ \\
$\begin{array}{l}\text { Total controls } \\
(\mathrm{n}=207)\end{array}$ & $0.47(59)$ & $0.42(53)$ & $0.11(14)$ \\
$\begin{array}{l}D Q A 1 * 0101 \text { Patients } \\
(\mathrm{n}=28)\end{array}$ & $0.51(105)$ & $0.42(86)$ & $0.08(16)$ \\
$\begin{array}{l}D Q A 1 * 0101 \text { Controls } \\
(\mathrm{n}=33)\end{array}$ & $0.67(22)$ & $0.30(10)$ & $0.03(1)$ \\
\hline
\end{tabular}

for the 15 comparisons made $\left(\mathrm{X}_{2}=11.48 ; 2\right.$ degrees of freedom, $\mathrm{p}=0.003$, pcorr $=0.045$ ). $H L A-D Q A 1 * 0101$ patients had a higher frequency of the $12.5 \mathrm{~kb} B g l \mathrm{II}$ fragment (26 of 56 alleles) than did either $H L A-D Q A I * 0101$ controls (12 of 66 alleles; $\mathrm{X}_{2}=11.12 ; \mathrm{p}=0.00085$; pcorr $=0.01)$ or $H L A-D Q A 1 * 0101$ negative patients $(48$ of 186 alleles; $\mathrm{X}_{2}=8.62 ; \mathrm{p}=0.003$; pcorr $=0.045$; Table
Table 2. Tcrb-V6.1/Bgl II RFLP allele frequencies in $D Q A 1 * 0101$ positive and negative patients and controls.

\begin{tabular}{llcc}
\hline Subjects & \multicolumn{3}{l}{ Number of alleles in each category } \\
\hline Patients & 12.5 & 5.7 & Total \\
$D Q A I^{*} 0101^{+}$ & 26 & 30 & 56 \\
$D Q A I^{*} 0101^{-}$ & 48 & 138 & 186 \\
Controls & & & \\
$D Q A I^{*} 0101^{+}$ & 12 & 54 & 66 \\
$D Q A I^{*} 0101^{-}$ & 103 & 235 & 338 \\
\hline
\end{tabular}

2). Overall, 21 of the 121 patients who were HLA typed (17.4\%) carried both the $H L A-D Q A 1 * 0101$ allele and a $12.5 \mathrm{~kb} \mathrm{Bgl}$ II fragment compared to 11 of the 191 HLA-typed controls $\left(5.5 \% ; \mathrm{X}_{2}=10.82 ; \mathrm{p}=0.001\right.$; pcorr $=0.008$ ), conferring a relative risk for disease of 3.65 .

Sequence variation in the Tcrb-V6.1 gene. The five individuals who were homozygous for the $12.5 \mathrm{~kb}$ polymorphic fragment and the five who were homozygous for the

Nucleotide Sequence

V6.1A CCA ATT TCA GGT CAT ACT GCC CTT TAC TGG TAC CGA CAA AGC CTG GGG CAG GGC CCA GAG TTT CTA ATT TAC TTC CAA V6.1B

GGC ACG GGT GCG GCA GAT GAC TCA GGG CTG CCC AAC GAT CGG TTC TTT GCA GTC AGG CCT GAG GGA TCC GTC TCT ACT CTG

AAG ATC CAG CGC ACA GAG CGG GGG GAC TCA GCC GTG TAT CTC TGT GCC

Amino Acid Sequence (Predicted)

V6.1A Pro Ile Ser Gly His Thr Ala Leu Tyr Trp Tyr Arg Gln Ser Leu Gly Gln Gly Pro Glu Leu Leu Ile Tyr Phe Gln Gly Thr Gly Ala Ala Asp Asp Ser Gly V6.1B

Leu Pro Asn Asp Arg Phe Phe Ala Val Arg Pro Glu Gly Ser Val Ser Thr Leu Lys Ile Gln Arg Thr Glu Arg Gly Asp Ser Ala Val Tyr Leu Cys Ala -

Fig. 1. Tcrb-V6.1 gene and derived amino acid sequences following PCR amplification from $B g l$ II restriction fragment (12.5 kb, $5.7 \mathrm{~kb}$ ) templates. The oligonucleotides and amino acids distinguishing V6.IA and $B$ alleles are shown (positions 62 and 84 ). 
$5.7 \mathrm{~kb}$ polymorphic fragment (see Materials and methods) yielded 47 and $23 T c r b-V 6$ gene clones, respectively, after PCR amplification and $\mathrm{m} 13$ subcloning. DNA sequence data obtained from these clones revealed two Tcrb$V 6.1$ gene sequences, $V 6.1 A$ and $V 6.1 B$ (Fig. 1). Sequence $V 6.1 B$ has not, to our knowledge, been described previously. It differs from sequence $V 6.1 A$ by two single bp substitutions, an adenine for a cytosine at position 132 of the amplified fragment and an adenine for a guanine at position 197 of the amplified fragment. These substitutions occurred as paired changes in all 70 clones examined. Since the 4D1 cDNA is a partial length clone lacking 54 nucleotides at the $5^{\prime}$ end of the $V$ gene coding sequence, these changes would result in substitution of a lysine (AAA) for an asparagine (AAC) at position 62 of the $\mathrm{Tcr}$ $\beta$ chain and a glutamine (CAG) for an arginine (CGG) at position 84 of the Tcr $\beta$ chain. Neither change results in the creation of a new $B g l$ II restriction site.

Correlation of allelic sequence variation with Tcrb-V6.1 gene RFLP. The sequence data obtained from clones allowed the design and use of allele-specific oligonucleotide (ASO) probes that hybridized to regions spanning the newly identified substitutions (Fig. 1) thus distinguishing sequences V6.1A and $\mathrm{B}$. In view of previous reports documenting frequent recombination within the Tcra and $b$-V regions (Seboun et al. 1989; Charmley et al. 1990) such oligonucleotide probes were initially used to ascertain the correlation between the TcrbV6.1/Bgl II RFLP and the two V6.1 gene sequences in individuals carrying different RFLP genotypes. PCRamplified genomic DNA samples were initially analyzed with the $V 6.1 \mathrm{~N}$ and $K$ probes defining sequences $V 6.1 A$ and $B$, respectively (see Materials and methods). Samples from all individuals homozygous for the $5.7 \mathrm{~kb} \mathrm{BglII} \mathrm{frag-}$ ment (patient $\mathrm{n}=38$; control $\mathrm{n}=28$ ) hybridized only to the $V 6.1 N$ probe indicating the presence of sequence $V 6.1 \mathrm{~A}$, while samples from all $12.5 \mathrm{~kb}$ homozygotes (patients $\mathrm{n}=14$; controls $\mathrm{n}=16$ ) hybridized only to the $V 6.1 \mathrm{~K}$ probes, indicating the presence of sequence $V 6.1 B$ (Fig. 2). Additional individuals, heterozygous at the $B g l$ II RFLP locus (patient $n=37$; control $n=34$ ), were oligotyped and shown to possess both $T c r b$ V6.1 sequence variants. $T c r b$ $V 6.1 A$ and $V g .1 B$ therefore represent allelic variants that correlate absolutely with the $5.7 \mathrm{~kb}$ and $12.5 \mathrm{~kb} \mathrm{Bgl} \mathrm{II}$ RFLP alleles, respectively.

Results obtained with the $V 6.1 N$ and $V 6.1 K$ probe pair were verified in additional dot-blot analyses on 36 samples, using the V6.1R and $V 6.1 Q$ probes (Fig. 1).

Tcrb-V6.1 allelic sequence variations and disease. The $V 6.1 B$ gene was present in 19/26 HLA-DQA1*0101 patients, compared with $11 / 33$ of the $H L A-D Q A 1 * 0101$ controls $\left(\mathrm{X}^{2}=9.19 ; \mathrm{p}=.001\right)$.
A)

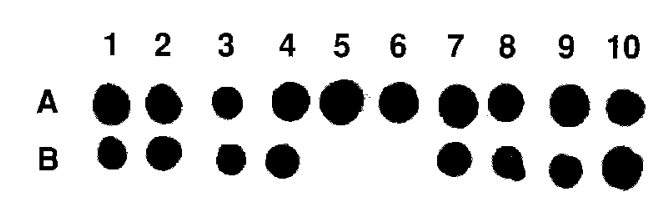

Dot Blot Probed with ASO probe III (6.1A sequence)

B)

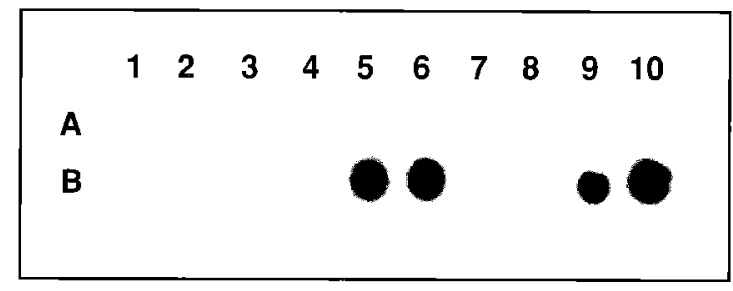

Dot Blot Probed with ASO probe IV (6.1B sequence)

\section{A $1-10, B 1-4$ \\ B 9-10}

Controls:

B $5-6$
B $7-8$
$5.7 \mathrm{~Kb}$ homozygotes

$5.7 / 12.5 \mathrm{~Kb}$ heterozygotes

$12.5 \mathrm{~Kb}$ homozygotes

$5.7 \mathrm{~Kb}$ positive sequence clones

\section{Discussion}

This study demonstrates the association of a Tcrb $V$ region gene polymorphism with one subtype of JRA in the context of a particular $H L A$ class II allele, $H L A-D Q A 1 * 0101$. These findings thus support a possible contribution by this $T c r b-V$ gene to at least one human autoimmune disease, EOPA-JRA.

Sequence data obtained on PCR-amplified DNA derived from restriction fragment templates that contain $T c r b$ $V 6.1$ genes, indicated proximity of the $B g l$ II RFLP to a $V 6.1$ gene locus containing two V6.1 gene allelic variants. One such variant, $V 6.1 B$, represents a previously undescribed $V 6.1$ gene sequence.

Comparison of the $V 6.1 A$ and $B$ gene sequences indicates a high degree of sequence conservation, consistent with two previous reports. Robinson (1989) described a single bp substitution within the coding region of the Tcrb $V l$ gene, and $\mathrm{Li}$ and co-workers (1990) reported two bp substitutions in the coding region of the Tcrb-V6.7 gene. Additional sequence variability of the V6.1 gene at the extreme $5^{\prime}$ and $3^{\prime}$ ends cannot be excluded however. The 4D1 cDNa (Leiden and Strominger 1986) used as the Tcrb V6.1 gene probe in the present study is a partial length 
clone, lacking 54 nucleotides at the $5^{\prime}$ end of the coding region sequence. Furthermore, the $3^{\prime}$ V6.1 gene primer annealed to the 4D1 cDNA template nine nucleotides upstream of the $V-D$ region junction. Sequences at the extreme $5^{\prime}$ and $3^{\prime}$ ends of the $V 6.1$ gene coding sequence were therefore not included in our PCR-amplified fragment. However, the finding of only two V6.I gene alleles is consistent with previous studies demonstrating limited allelism in human and murine $T c r-V$ genes (Robinson 1989; Li et al. 1990; Pullen et al. 1990; Posnett 1990).

The similarities between framework regions of Tcr molecules and immunoglobulins permit the construction of structural models of the Tcr molecule based on known immunoglobulin structure (Chothia et al. 1988). The two nucleotide differences between allelic variants $V 6.1 A$ and $V 6.1 B$ result in non-conservative amino acid substitutions at positions 62 and 84 of the Tcrb chain. Both positions represent sites of intermediate residue variability and each appears to be located in the loops between b-sheet framework strands. Position 62 is thought to lie close to the Tcr equivalent of the second hypervariable region of $\mathrm{Ig}($ Davis and Bjokman 1988) and therefore may influence antigen/MHC recognition.

Consideration of the role played by $T c r b-V 6.1$ genes in the pathogenesis of EOPA-JRA must include the observation that $H L A-D Q A I^{*} 0101$ patients are more likely to possess a $V 6.1 B$ gene and less likely to possess a $V 6.1 \mathrm{~A}$ gene in their genomic repertoire. A possible etiologic role for the $V 6.1 B$ allele in disease susceptibility would be consistent with previous reports assigning a dominant role for $\mathrm{T}$ cells expressing particular variable genes in animal models of autoimmunity (Urban et al. 1988; Acha-Orbea et al. 1988). Alternatively, the decreased frequency of the V6.1A gene segment in $H L A-D Q A 1 * 0101$ patients could represent a "hole" in the available Tcr repertoire. Individuals lacking the V6. $1 \mathrm{~A}$ gene segment may be unable to eliminate foreign antigen(s) presented by $H L A-$ $D Q A 1^{*} 0101$; the antigen(s) may then act as an inciting arthritogen. Another possibility consistent with the concept of a "hole in the repertoire" is that the V6.1A gene segment encodes a suppressor receptor on T cells. Several epitopes derived from type II collagen have been shown to stimulate suppressor $T$ cells that confer protection against murine collagen-induced arthritis (Myers et al. 1989). Such suppressor T cells may be necessary to prevent establishment of chronic disease following the inciting antigenic stimulus or to prevent progression of disease to a polyarticular form.

These considerations do not adequately account for the occurrence of disease in $H L A-D Q A 1 * 0101$ individuals who are either heterozygous for the $V 6.1$ gene alleles or homozygous for V6.1A. HLA (Gulwani-Akolkar et al. 1991) and non-HLA influences on thymic selection of expressed Tcrs in the periphery may result in preferential expression of $V 6.1 B$ rather than $V 6.1 A$ in heterozygotes.
Thus, $H L A-D Q A 1^{*} 0101$, additional $H L A$ alleles, non$H L A$ alleles, and/or endogenous superantigens on thymic epithelial cells could positively select $\mathrm{T}$ cells bearing $V 6.1 B$ in preference to $V 6.1 A$ or, alternatively, could prevent the maturation of $\mathrm{T}$ cells bearing V6.1A (if such $\mathrm{T}$ cells are potentially self-reactive; Zhou et al. 1991). Additional considerations, of particular relevance to $V 6.1 \mathrm{~A}$ homozygotes, are the possible contributory roles of additional $T c r b-V$ gene segments, of $T c r a-V$ genes, and of sequence variation in the $D$ and $J$ regions of the Tcr $\beta$ chain.

Other reports support the suggestion that gene complementation between $T c r b-V$ genes and $H L A-D Q$ alleles may contribute to disease chronicity in arthritis patients. In the murine model of collagen arthritis, development of disease is dependent on the presence of a $T c r$ haplotype carrying a full complement of $T c r b V$ genes and an allelic variant of the I-A chain carried on the $H 2^{q}$ haplotype (Banerjee et al. 1988; Holmdahl et al. 1989). The concept of $T c r / H L A$ gene complementation has also received experimental support from studies of animal models of systemic lupus (Yanagi et al. 1986; Ghatak et al. 1987) and of a subgroup of systemic lupus erythematosus (SLE) patients with anti-Ro antibodies (Frank et al. 1990).

The advantage of segregating patients on an immunogenetic basis was supported by our ability to isolate individuals who were at increased risk of suffering progressive disease. Further insight into immunopathologic mechanisms will require studies of $\mathrm{Tcr}$ expression in diseased tissue. Such investigation may provide the rationale for the development of highly specific immunotherapeutic strategies based on Tcr epitope-specific reagents.

Acknowledgments. The authors wish to express their appreciation to Martin G. Larson for biostatistical advice, to Louise Kittredge for editorial assistance, and to Carolyn Keith Haun for preparation of the manuscript. This research was supported by grants from the Arthritis Foundation, Alberta Heritage Foundation for Medical Research (fellowship for WM), Lions' Clubs of Ohio, National Institutes of Health RO1 \#AR39979, Schmidlapp Foundation, and Children's Hospital Research Foundation, Cincinnati, Ohio.

\section{References}

Acha-Orbea, H., Mitchell, D. J., Timmermann, L., Wraith, D. C., Tausch, G. S., Waldor, M. K., Zamvil, S. S., McDevitt, H. O., and Steinman, L.: Limited heterogeneity of T-cell receptors from lymphocytes mediating autoimmune encephalomyelitis allows specific immune intervention. Cell 54: 263-273, 1988

Banerjee, S., Haggi, T. M., Luthra, H. S., Stuart, J. M., and David, C. S.: Possible role of V beta T-cell receptor genes in susceptibility to collagen-induced arthritis in mice. J Exp Med 167: 832-839, 1988

Barth R., Kim, B., Lan, N., Hunkapiller, T., Sobriele, N., Winoto, A., Gershenfeld, M., Oliada, C., Hansburg, D., Weissman I., and Hood, L.: The murine $\mathbf{T}$-cell receptor employs a limited repertoire of expressed $\mathrm{V}_{\beta}$ gene segments. Nature 316: 517-522, 1985 
Cassidy, J. T., Levinson, J. E., Bass, J. C., Baum, J., Brewer, E. J., Fink, C. W., Hanson, V., Jacobs, J. C., Masi, A. T., Schaller, J. G., Fries, J.E., McShane, D., and Young, D.: A study of classification criteria for a diagnosis of juvenile rheumatoid arthritis. Arthritis Rheum 29: 274-281, 1986

Charmley, P., Concannon, P., and Gatti, R. A.: Lack of linkage disequilibrium between Tcr-beta variable and constant genes: implications for disease associations. FASEB $J s$ (Suppl 4): A661, 1988

Charmley P., Chao, A., Concannon, P., Hood, L., and Gatti, R. A.: Haplotyping the human $\mathrm{T}$-cell receptor $\beta$-chain gene complex by use of restriction fragment length polymorphisms. Proc Natl Acad Sci USA 87: 4823-4827, 1990

Chothia, C., Boswell, D.R., and Leslie, A. M.: The outline structure of the T-cell $\alpha \beta$ receptor. EMBO J 7: 3745-3755, 1988

Davis, M. M. and Bjorkman, P. J.: T-cell antigen receptor genes and T-cell recognition. Nature 334: 395-402, 1988

Demaine, A. G., Ratanchiya, S., Pope, R., Ewins, D., Millward, B. A., and McGregor, A. M.: Thyroglobulin antibodies in Graves' disease are associated with T-cell receptor beta chain and major histocompatibility complex loci. Clin Exp Immunol 77: 21-27, 1989

Feinberg, A. P. and Vogelstein, B.: A technique for radiolabelling DNA restriction endonuclease fragments to high specific activity. Analyt Biochem 132: 6-18, 1983

Frank, M. B., McArthur, R., Marley J. B., and Fujisaku, A.: Anti-Ro (SSA) autoantibodies are associated with T-cell receptor $\beta$ genes in systemic lupus erythematosus patients. $J$ Clin Invest $85: 33-39$, 1990

Ghatak, S., Sainis, K., Owen, F. L., and Datta, S. K.: T-cell receptor beta- and I-A beta chain genes of normal SWR mice are linked with the development of lupus nephritis in NZB $\times$ SWR crosses. Proc Natl Acad Sci USA 84: 6850-6853, 1987

Gulwani-Akolkar, B., Gregersen, P. K., Akolkar, P., Manji, R., Janson, C. H., Posnett, D., and Silver, J.: HLA genes influence the human T-cell receptor repertoire. FASEB J 5: A7718, 1991

Holmdahl, R., Karlsson, M., Andersson, M.E., Rask, L., and Andersson, L.: Localization of a critical restriction site on the I-A chain that determines susceptibility to collageninduced arthritis in mice. Proc Natl Acad Sci USA 86: 9475-9479, 1989

Jones, N., Leiden, J., Dalynas, D., Fraser, J., Clabby, M., Kishimoto T., and Strominger, J. L.: Partial primary structure of the alpha and beta chains of human tumor T-cell receptors. Science 227: 311-314, 1984

Lai, E., Concannon, P., and Hood, L.: Conserved organization of the human and murine T-cell receptor beta-gene families. Nature 331: 543-548, 1989

Leiden, J. M., and Strominger, J. L.: Generation of diversity of the betachain of the human T-lymphocyte receptor for antigen. Proc Natl Acad Sci USA 83: 4456-4461, 1986

Li, Y., Szabo, P. Robinson, M.A., Dong, B., and Posnett, D. N.: Allelic variations in the human $\mathrm{T}$-cell receptor $\mathrm{V}_{\beta} 6.7$ gene products. J Exp Med 171: 221-230, 1990
Maksymowych, W.P., Gabriel, C. A., Luyrink, L., Van Kerckhove, C., Leiden, J., Choi E., and Glass, D. N.: Polymorphic markers related to a single $\mathrm{Tcr}_{\beta}$ V6 gene segment. Immunogenetics 33: 281-285, 1991

Millward, B. A., Welsh, K. I., Leslie, R. D. G., Pyke D. A., and Demaine, A.G.: T-cell receptor beta chain polymorphisms are associated with insulin-dependent diabetes mellitus. Exp Immunol 70: $152-157,1987$

Mittal, K. K., Mickey, M. Rr., Singal, E. R., and Terasaki, P.: Serotyping for homotransplantation. VIII. Regimen of microdroplet lymphocyte cytotoxicity test. Transplantation 6: 913-927, 1968

Myers, K. L., Stuart, J. M., Seyer, J. M., and Kang, A. H.: Identification of an immunosuppressive epitope of Type II collagen that confers protection against collagen-induced arthritis. J Exp Med 170: 1999-2010, 1989

Posnett, D. N.: Allelic variations of human Ter V gene products. Immunol Today 11: 368-373, 1990

Pullen, A. M., Potts, W., Wakeland, E. K., Kappler J., and Marrack, P.: Surprisingly uneven distribution of the $\mathrm{T}$ cell receptor $\mathrm{V}_{\beta}$ repertoire in wild mice. $J$ Exp Med 171: 49-62, 1990

Robinson, M. A.: Allelic sequence variations in the hypervariable region of a T-cell receptor beta chain: Correlation with restriction fragment length polymorphism in human families and populations. Proc Natl Acad Sci USA 86: 9422-9426, 1989

Seboun, E., Robinson, M. A., Doolittle, T. H., Ciulla, T. A., Kindth, T. J., and Hauser, S. L.: A susceptibility locus for multiple sclerosis is linked to the T-cell receptor $\mathrm{B}$ chain complex. Cell 57: 1095-1110, 1989

Tebib, J. G., Alcocer-Varely, J., Alarcon-Segovia, D., and Schur, P. H.: Association between a T-cell receptor restriction fragment length polymorphism and systemic lupus erythematosus. J Clin Invest 86: 1961-1967, 1990

Urban, J. L., Kumar, V., Kono, D. H., Gomez, C., Horwath, S. J., Clayton, J., Ando, D. G., Sercarz, E. E., and Hood, L.: Restricted use of $\mathrm{T}$-cell receptor $\mathrm{V}$ genes in murine autoimmune encephalomyelitis raises possibilities for antibody therapy. Cell 54 : $577-591,1988$

Van Kerckhove, C., Luyrink, L., Taylor, J., Melin-Aldana, H., Balakrishnan, K., Maksymowych, W., Elma, M., Lovell, D. J., Choi, E., and Glass, D. N.: HLA-DQA $1 * 0101$ influences disease outcome in EOPA-JRA. $J$ Rheumatol, 18: 874-879, 1991

Yanagi, Y., Hirose, S., Nagasawa, R., Shirai, T., Mak, T. W., and Tada, T.: Does the deletion within $\mathrm{T}$-cell receptor beta-chain gene of NZW mice contribute to autoimmunity in $(\mathrm{NZB} \times \mathrm{NZW})$ F1 mice 2. Eur J Immunol 16: 1179-1182, 1986

Zhou, P., Anderson, G. D., Savanirayan, S., Inoko, M., and David, C.S.: Human HLA-DQb chain presents minor lymphocyte stimulating locus gene products and clonally deletes Tcr Vb6+, $\mathrm{Vb8.1}+\mathrm{T}$ cells in single transgenic mice. Hum Immunol 31: 47-56, 1991 